SII-1a

\title{
Estimation of the Global Solar Radiation Received on the Soil in Nalohou and Natitingou (Northern Benin)
}

\author{
Gabin Koto N'Gobi1', Hagninou E. V. Donnou1, Médard Agbazo1, Aristide. B. Akpo1, Basile. \\ B. Kounouhewa ${ }^{1}$ \\ Email: kotgabin36@yahoo.fr
}

\section{Abstract}

The design of solar energy systems requires knowledge of the global solar radiation received by solar panels on the ground. However, for many developing countries such as the Benin Republic, there is a serious lack of radiometric stations everywhere in the country. The unavailability of these data, therefore, limits knowledge regarding the optimal functioning of solar installations. To cope with these difficulties, a method for estimating the global irradiation is developed at Nalohou AMMA CATCH station and Natintingou synoptic station, two sites in North-West Benin. This model depends on meteorological and astronomical parameters. Meteorological data such as sunshine duration, relative humidity, and air temperature have been collected on the synoptic station of Natitingou, and observed data of irradiation are collected from Nalohou. They are used to validate the model. The results show that the estimation of the mean square deviation value is around $10^{-2}$. Overall solar radiation is significant in this region and its annual average value varies between $9.80 \mathrm{kWh} / \mathrm{m}^{2}$ and $10.50 \mathrm{kWh} / \mathrm{m}^{2}$. This model can, therefore, be used by solar system operators to optimize energy production in the region.

\section{Introduction}

Access to energy is essential for the social and economic well-being of populations worldwide. In most African developing countries, energy accessibility is difficult despite the high potential of renewable sources of energy. Among these sources of renewable energy, solar energy is considered as the most efficient, the best alternative resource [1] adapted for providing heat, electricity, and water in rural and urban areas. However, accurate knowledge of the incoming solar radiation resource at a site is required for the design and the efficiency in the estimation of any solar energy system [2]. Let's remember that solar plants functioning depends mainly on the climatic conditions of the specific location [3]. In Benin Republic (West Africa), few stations consistently measure global daily solar radiation. But, the lack of reliable data on global solar radiation can lead to erroneous evaluation of the solar pants efficiency. Therefore, the availability of certain climatic parameters such as relative humidity, air temperature, and astronomical parameters are necessary for the construction of an empirical model [4,5]. In the literature, several empirical formulations have been developed to predict global solar radiation using several meteorological variables such as sunshine duration, cloud cover, relative humidity, maximum temperature, water vapor pressure, etc. [4-9]. Quansah et al. [10] proposed an empirical model for estimating Global Solar Radiation (GSR) as a function of the sunshine relative duration over the Ashanti region in Ghana. The model can predict very well the pattern of the measured monthly daily mean GSR for the entire period of study with the smallest values of errors. Trabea and Shaltout [7] established a model in which input depends on the mean daily

1 Laboratoire de Physique du Rayonnement (LPR), Faculté des Sciences et Techniques (FAST), Université d'Abomey-Calavi (UAC), 01 B.P. 526, Cotonou, Benin. 
maximum temperature, the mean daily relative humidity, the mean daily sea level pressure, the mean daily vapor pressure, and hours of sunshine in Egypt. The Results show values of correlation coefficients varying from $89 \%$ to $99 \%$ and the errors of estimation are between 0.01 and 0.04. The Angstrom-type model also allows estimating the global solar irradiance by simple linear regression. It has been used by several authors [10-12]. Falayi et al [4, 12,13] correlated global solar radiation and meteorological parameters using monthly mean daily global solar radiation, sunshine duration, temperature, and relative humidity data from Nigeria. Several other authors such as Karoro et al [14], Coulibaly and Ouedoraogo [15], Onyango and Ongoma [16], Yisehak [17], Afungchui and Neba [18], Adeola et al [19], Safari and Gasore [2], Hassan et al. [20], Dankassoua [21], Ajayi et al. [22], Olomiyesan et al. [23] have established models for determining GSR. These authors have estimated global solar radiation in several areas of Africa. The diversity of methods for estimating global solar radiation to improve the design and optimization of solar energy systems clearly shows the interest given by authors on this topic. However, the reliability of these models depends largely on the strong correlation between estimated and measured variables, and many models (from cited above) have shown their limitations the reproduce GSR at other sites. Very few studies have experimented with the estimation of global solar radiation in Benin. One can cite Amoussa [24] who is the first to provide information on the characteristics of solar radiation in Benin using a linear model from Frère and Rietveld's to determine correlation constants of dimensionless parameters for many stations located in Benin. Unfortunately, the linear model is not reliable everywhere to reproduce global solar radiation measurements in the country. To overcome this lack in the current study, we develop and validate a global solar radiation model, capable of better estimation of solar radiation at the ground Surface in Nalohou, a typical and nearest village of Natitingou synoptic station where observed data are available. The reason behind the choice of the location is that solar radiation's data are available for some period in the location. So that we can easily calibrate the model with data recorded at the Nalohou station and regenerate those of Natintingou. This model was then used to generate global solar radiation at this meteorological site with the same meteorological parameters, geographical and topographical characteristics as Nalohou. The remaining parts of the paper are organized as follows: in section 3 , study sites, the dataset, and methods are described. Analysis of results and their interpretations are made in section 4. Finally, we conclude the paper with a summary and outlook for further research in section 5 .

\section{Materials and Methods}

\subsection{Materials}

\subsubsection{Study sites}

Benin is located between latitudes $6^{\circ} 30-12^{\circ} 30 \mathrm{~N}$ and longitudes $1^{\circ}-4^{\circ} \mathrm{E}$. It is bordered in the North by the Niger River, in the North-West by Burkina Faso, in the West by Togo, in the East by Nigeria and in the South by the Atlantic Ocean. Two (02) study sites (Nalohou and Natitingou) are chosen in this study. Nalohou AMMA CATCH station is located in the Donga watershed in northern Benin, where the global solar radiation model is developed and used to estimate this parameter at Natitingou, the nearest synoptic meteorological station $(\sim 70 \mathrm{~km})$. The climate in these two locations is Sudanian and characterized by a single dry season from October or November to February or March and a single rainy season from April to October. Figure 1 and Table 1 show the location and the geographical characteristics of these two sites. The rainy seasons transport humid air from the Atlantic Ocean into the continent when the Intertropical Front (ITF) advances toward the North. The dry seasons release a mixture of dusty and dry air 
from the Sahara toward the Atlantic Ocean when the ITF is fastly returning to the south. Natitingou is the Rainiest región of the country (1300 mm/year).

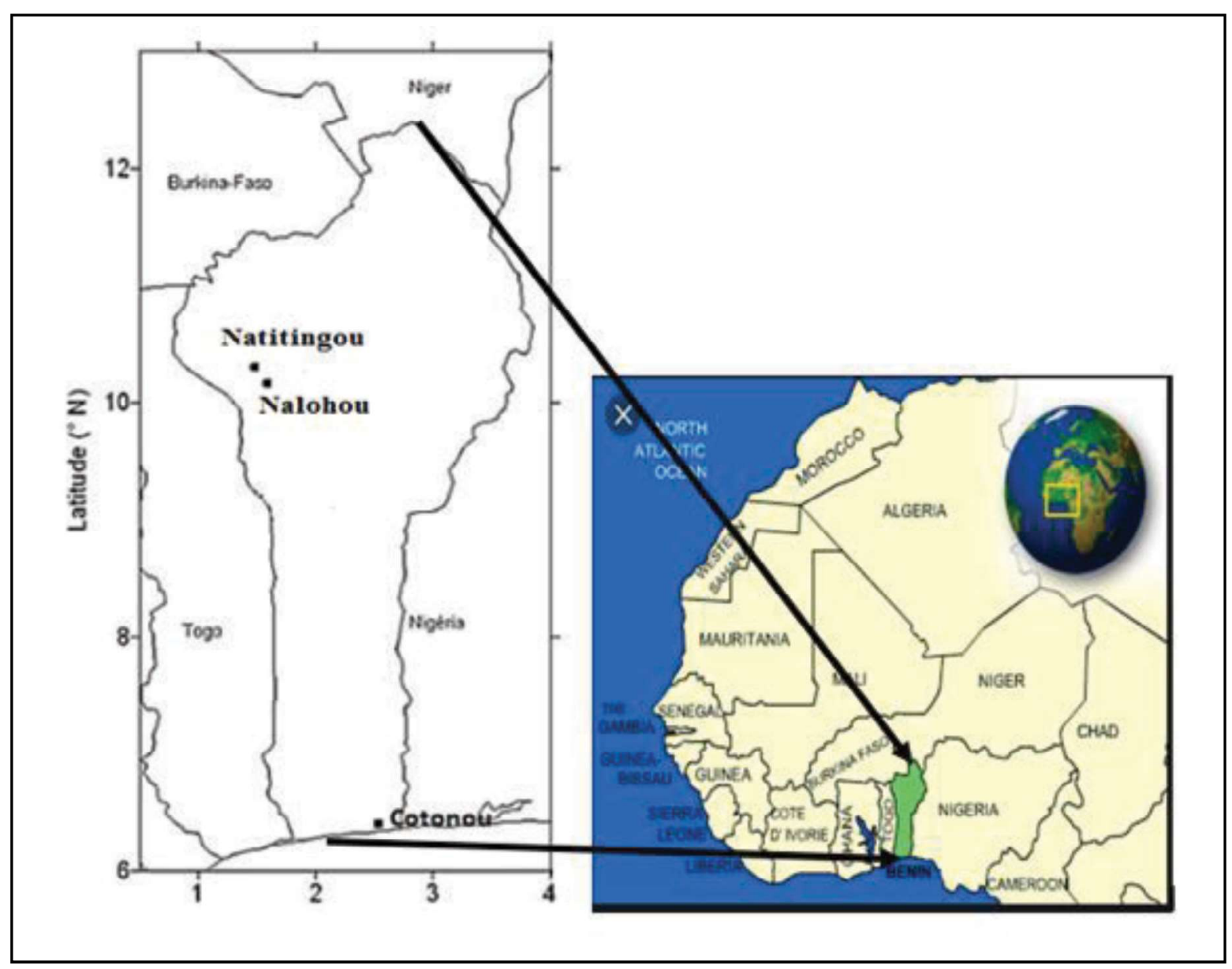

Figure 1: Geographical location of the study sites

Table 1: Geographical characteristics of study sites

\begin{tabular}{|c|c|c|c|}
\hline Site & Latitude & Longitude & Altitude (m) \\
\hline Natitingou & $10^{\circ} 19^{\prime} \mathrm{N}$ & $1^{\circ} 23^{\prime} \mathrm{E}$ & 426 \\
\hline Nalohou & $9^{\circ} 744 \mathrm{~N}$ & $1^{\circ} 60 \mathrm{E}$ & 449 \\
\hline
\end{tabular}

\subsubsection{Data used}

At the Nalohou site, global solar radiation data and meteorological parameters such as ambient air temperature and air relative humidity are measured during the AMMA CATCH project at $2 \mathrm{~m}$ above ground level every $15 \mathrm{~min}$ in the period from July 10, 2007, to July 10, 2010 [25]. As insolation data was not measured at Nalohou, the data recorded at Natitingou was used during the same period. Data were split into two parts: (i) one part covers the period from July 10, 2007, to July 09, 2009 and used to develop the new model; (ii) the second part covers the period from 10 July 2009 to 10 July 2010 which were used to validate the proposed model. Figure 2 gives us an overview of the Nalohou experiment site showing the installed solar radiation sensor. 


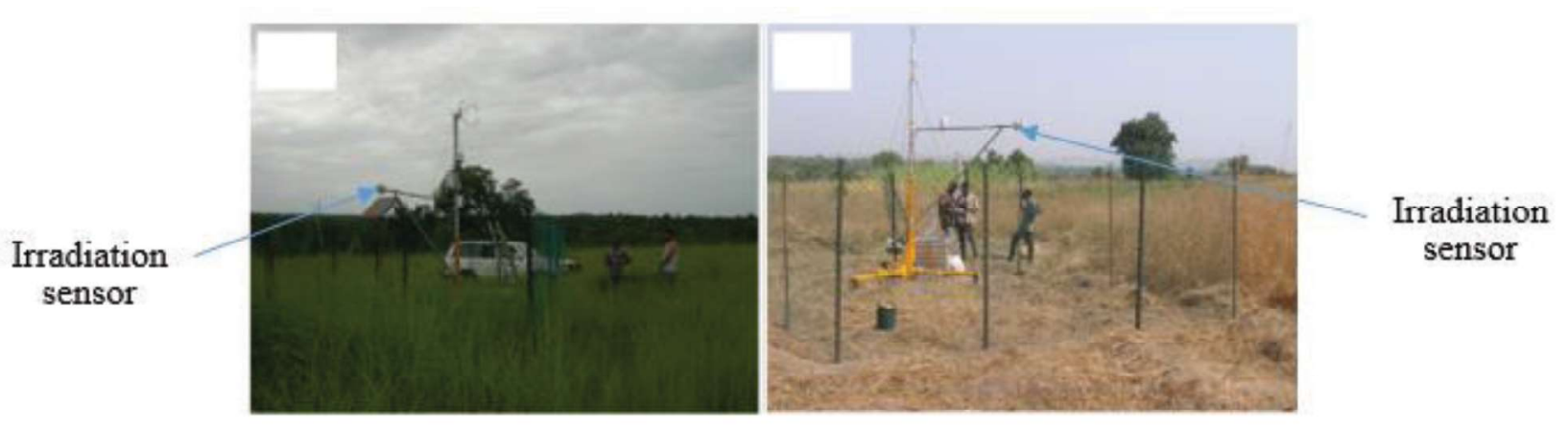

Figure 2 : Nalohou experimental site (Mamadou [25])

Natitingou site is a synoptic meteorological station of the National Meteorological Agency (ANM). Insolation duration, ambient air temperature, air relative humidity was used as input parameters in the developed model to estimate the global solar radiation at this site. These meteorological parameters were measured hourly over the period from 1st January 2016 to 31 December 2016.

\subsection{Methods}

\subsubsection{Formulation of the new model}

In the work of Chukwujindu [26] who reviewed more than 760 different models for estimating global solar radiation in Africa, we noted that most of the models are based on the Angstrom formulation which is a function of the solar fraction.

Let us thus consider the relation between the components of the global solar irradiation on a horizontal plane and the fraction of insolation given by Angström in Hinrichsen 1994 [27]:

$$
\frac{\mathrm{H}}{\mathrm{H}_{0}}=\mathrm{a}+\mathrm{b \sigma}
$$

$\mathrm{H}\left(\mathrm{W} / \mathrm{m}^{2}\right)$ is the global solar irradiation on a horizontal plane, a and $\mathrm{b}$ are model calibration constants, $\sigma$ is the fraction of daily sunstroke. It is expressed as:

$$
\sigma=\frac{n_{j}}{N_{o j}}
$$

$n_{j}$ is the insolation duration on the day j, expressed in hours $(h)$ and $N_{o j}$ is the astronomical duration, expressed as follows:

$$
\mathrm{N}_{\mathrm{oj}}=\frac{2}{15} \omega_{\mathrm{j}}
$$


$\omega_{\mathrm{j}}$ is the daily hourly angle of sunrise on a horizontal plane expressed in radians. It is given by:

$$
\omega_{\mathrm{j}}=\operatorname{Arcos}\left(-\tan \left(\delta_{\mathrm{j}}\right) \tan (\phi)\right)
$$

$\phi$ is the latitude in degrees and $\delta_{\mathrm{j}}$ is the daily solar declination in degrees:

$$
\delta_{\mathrm{j}}=23.45 \sin \left(\frac{360}{365}\left(\mathrm{~N}_{\mathrm{j}}+284\right)\right)
$$

with $\mathrm{Nj}$ being the number of the day counted from January 1st. The expression of the daily average $\mathrm{H}_{0}$ (in $\mathrm{W} / \mathrm{m}^{2}$ ) of solar irradiation from a horizontal plane outside the atmosphere is given by Tadili and Bargach [28]:

$$
\mathrm{H}_{0}=\frac{24}{\pi} \mathrm{I}_{\mathrm{o}}\left(\cos \left(\delta_{\mathrm{j}}\right) \cos (\phi) \sin \left(\omega_{\mathrm{j}}\right)+\omega_{\mathrm{j}} \sin \left(\delta_{\mathrm{j}}\right) \sin (\phi)\right)
$$

$\mathrm{I}_{\mathrm{o}}\left(\mathrm{W} / \mathrm{m}^{2}\right)$ is the corrected solar constant which expression is given by equation (7) as follows:

$$
I_{o}=1367\left[1+0.034 \cos \left(\frac{360}{365}\left(N_{j}-3\right)\right)\right]
$$

By analyzing the models of global solar radiation developed in Africa and reported in the work of Chukwujindu [26], the hybrid models established by several authors have proved to be more reliable than the other formulations encountered. However, no formulation of these Hybrid models exploited in Africa takes into account simultaneously the solar fraction at order greater than 1. The power form of the solar fraction as well as the ambient air temperature and relative humidity is often 1. In this study, we, therefore, preferred to estimate global solar radiation as a function of these meteorological variables.

In equation (1), we therefore optimally introduce the solar fraction with an unknown exponent $\alpha$, the ambient temperature $\left(\mathrm{T}_{\mathrm{a}}\right)$ and air relative humidity $\left(\mathrm{R}_{\mathrm{r}}\right)$ meteorological factors that directly influence global solar radiation. To further reduce the divergence between observation data and estimated ones, we have also introduced calibration constants for the proposed model. The expression of global solar radiation is given by equation (8) as follows:

$$
\frac{H}{H_{0}}=\left(a+b\left(\frac{n_{j}}{N_{o j}}\right)+c\left(\frac{n_{j}}{N_{o j}}\right)^{\alpha}+d T_{a}+e R H\right)
$$


$\alpha, c, d$, and $e$ are model calibration constants. All the constants $\alpha, a, b, c, d$, and $e$ are determined by numerical simulation of the Nelder-Mead simplex algorithm [29]. Indeed, the simplex algorithm, one of the most widely adopted methods for unconstrained nonlinear multidimensional optimization, was used in this study to better calibrate the proposed model. In the Matlab software, the function "fminsearch" was used to simulate this algorithm. "Fminsearch" finds the minimum of a scalar function of several variables, starting with an initial estimation. This is generally called unconstrained nonlinear optimization. The method consists of wrapping the minimum in a simplex. A simplex is a set of $(\mathrm{N}+1)$ points surrounding the minimum (a line in one dimension, a triangle in 2 dimensions, and a pyramid in 3dimension). Each simplex is characterized for $\mathrm{N}+1$ vectors at the vertices of the simplex. A new point is taken inside or next to the simplex at each calculation step. The value of the function at this point is compared with the values of the functions evaluated at the vertices. One of the vertices is then replaced by the new point generating a new simplex (by reflection, expansion, or contraction). The procedure is repeated as long as the diameter of the simplex is not smaller than a specified tolerance.

\subsubsection{Statistical Testing}

To evaluate the discrepancies between global solar radiation measurements and model estimates, the square root mean square error (RMSE) and absolute mean error (MAE) estimators were determined:

$$
\begin{aligned}
R M S E & =\sqrt{\frac{1}{n} \sum_{i=1}^{n}\left(p_{i}-f_{i}\right)^{2}} \\
M A E & =\frac{1}{n} \sum_{i=1}^{n}\left|\left(p_{i}-f_{i}\right)\right|
\end{aligned}
$$

Where $p_{i}$ represents measurements, $f_{i}$ the predictions and $\mathrm{n}$ the number of observations. When these estimators are low and close to zero the estimates are in agreement with the measurements.

\section{Resultats and discussion}

4.1 Daily variation of solar declination $\delta_{j}$, the irradiation out of the atmosphere $I_{0}$, the angle of sunrise $\omega_{j}$ and the astronomical length of the days $\mathbf{N}_{\mathbf{o j}}$

Figure 3 presents the variations of the astronomical parameters of the sun in the Nalohou AMMA $\mathrm{CATCH}$ measurement site. 

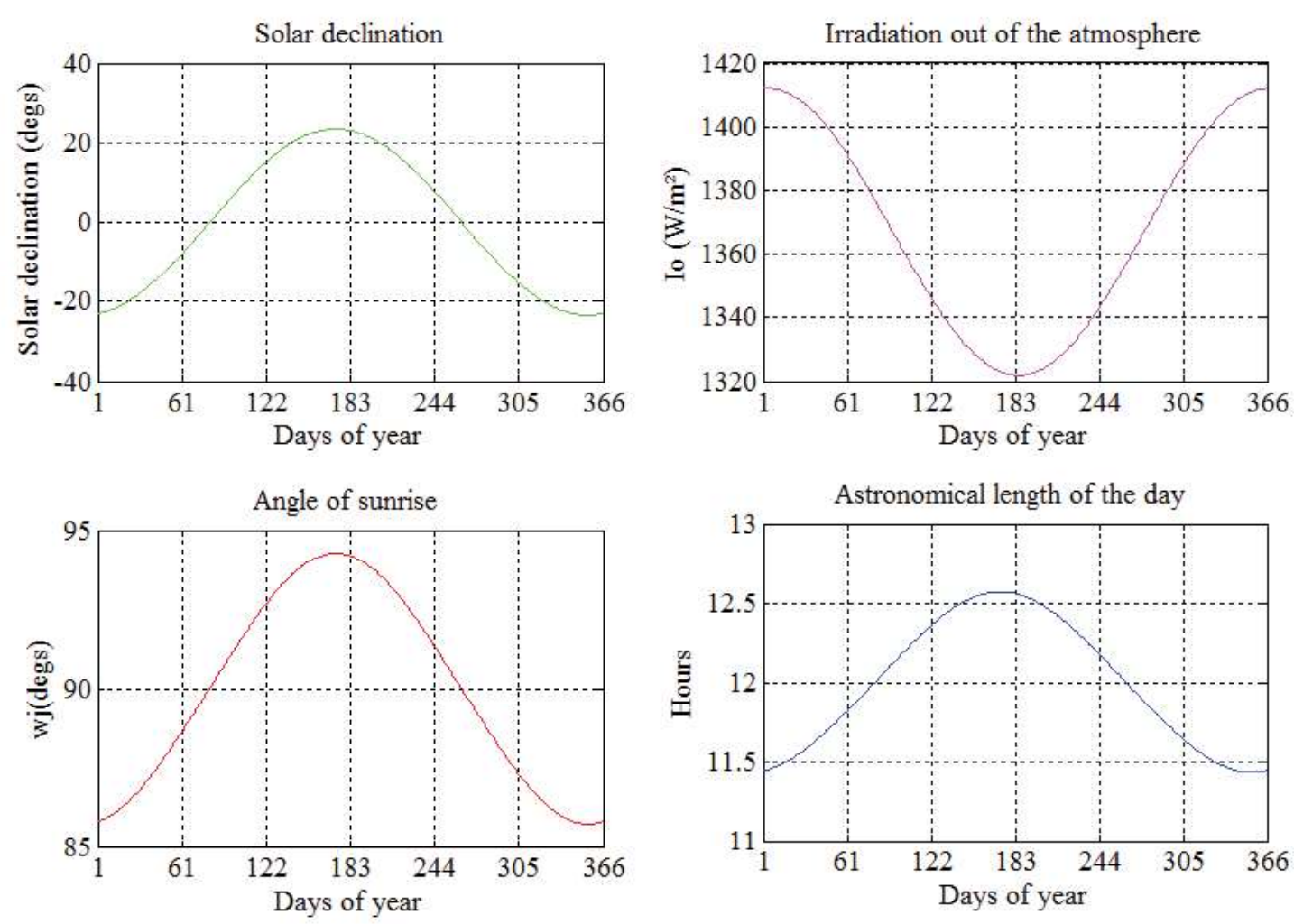

Figure 3: Daily mean variation of $\delta_{\mathrm{j}}, \mathrm{I}_{\mathrm{o}}, \omega_{\mathrm{j}}, \mathrm{N}_{\mathrm{oj}}$ during the year in Nalohou (2007-2009)

Sun's declination angle during the period from July 2007 to July 2009 varies on average from $19^{\circ}$ to $21^{\circ}$. The peak of this angle is observed in early July. The irradiation outside the atmosphere varies between $1320 \mathrm{~W} / \mathrm{m}^{2}$ and $1410 \mathrm{~W} / \mathrm{m}^{2}$ with the minimum recorded at the beginning of July. The angle of the sunrise is between $86^{\circ}$ and $94^{\circ}$ during the year and the astronomical length of the day varies from $11.4 \mathrm{~h}$ to $12.6 \mathrm{~h}$ with a peak always observed around the beginning of July. The lowest values of out of atmosphere irradiation are therefore reached when the sun's declination angle, the sunrise angle, and the astronomical length of the day are at their maximum values.

\subsection{Simulation and validation of the proposed model at Nalohou site}

Figures 4 and 5 present the results of the simulation from the proposed model using global solar radiation data measured at the Nalohou site. The calibration's constants of the model are also evaluated throughout the year. From figure 4, one can notice a seasonal variation of the solar irradiation. So, figure 5 is drawn to compare the seasonally observed data to those generated by the model. 


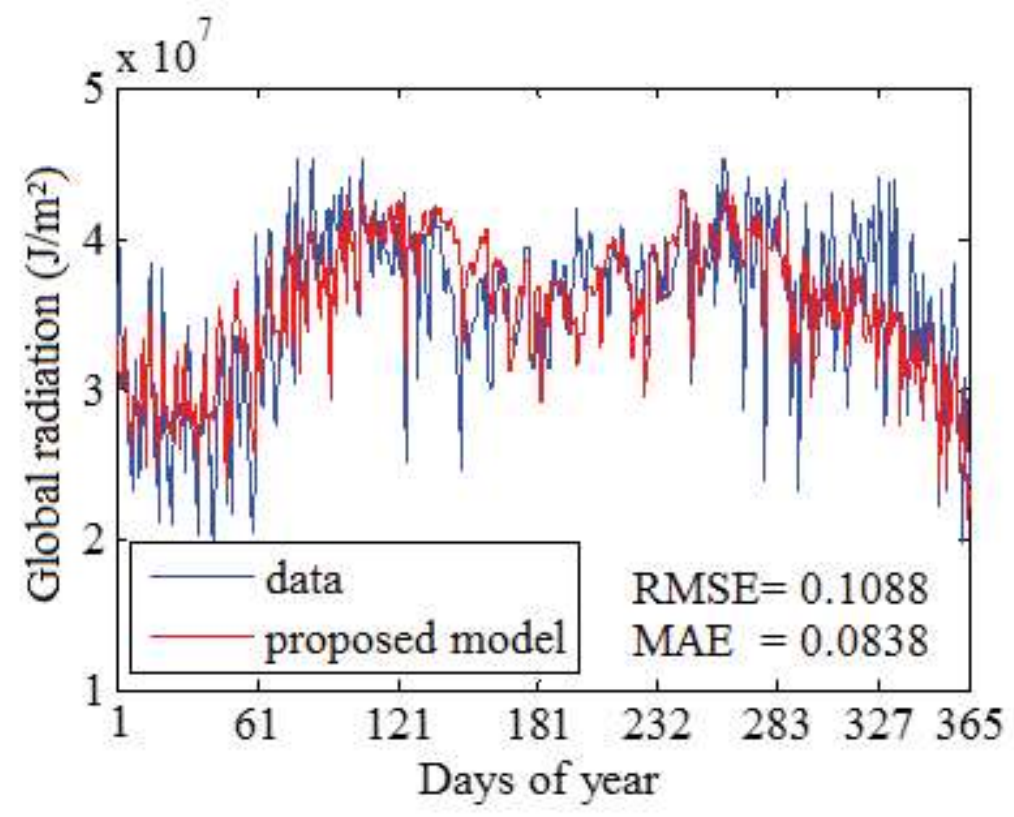

Figure 4: Correlation between the proposed model and the global solar radiation observed data for 2016
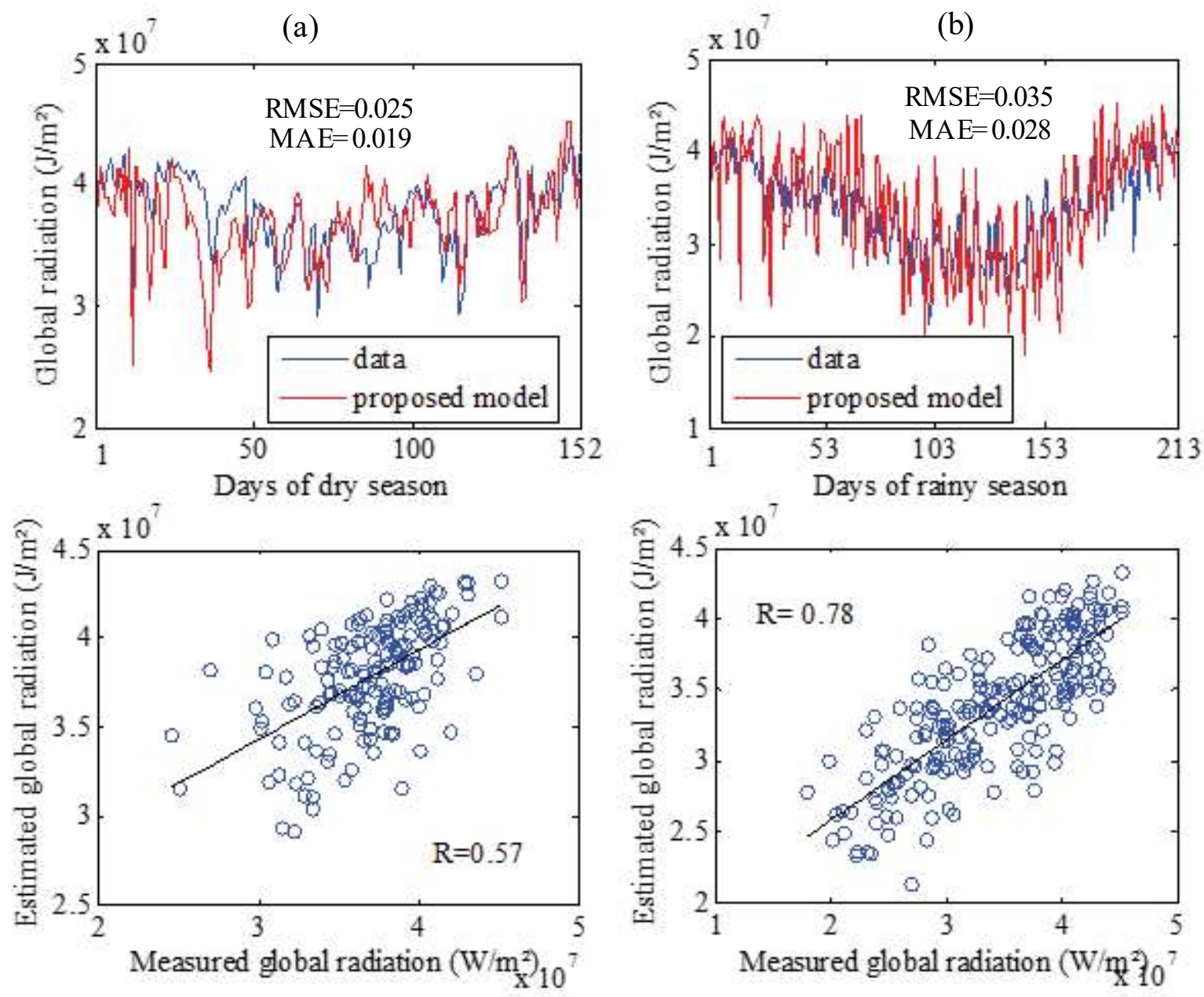

Figure 5: Correlation between proposed model estimates and global solar radiation data in 2016: (a) dry season and (b) rainy season 
The model proposed in this study and the measurements of global solar radiation generally show good agreement throughout the year. The error estimators of the square root mean square error (RMSE) and the absolute value of the mean error (MAE) values are 0.1088 and 0.0838 , respectively. Similarly, a seasonal analysis of the correlation between estimated values of GSR and observed data shows that during the dry season from November to March, the errors of estimates (RMSE, MAE) values are 0.025 and 0.019 respectively, showing the model's seasonal efficiency. During the rainy season from April to October, these values are 0.035 and 0.028 , respectively. One can notice that the seasonal error estimators are lower than those of the entire year 2016 form figure 4 . Therefore in the study site, the seasons have a greater influence on global solar radiation. From November to December, there is a divergence between the regenerated GSR values and the measurements. This observation is confirmed by the low value of the correlation coefficient obtained during the dry season (0.57). This gap could be due to the influence of "Harmattan" flux (dry air blowing from Sahara toward the Atlantic Ocean) in the study area at this period of the year. This dry and dusty wind brings suspended particulates maters in the atmosphere which could attenuate the global solar radiation received on the ground. A model integrating the aerosol rate in the atmosphere could therefore better reproduce this radiation sequence at our site during the period. On the other hand, during the rainy season, the measurements and the estimates values of GSR show the same direction of variation, justified by a fairly good value of the correlation coefficient (0.78). However, we note that the model slightly overestimates the measurements throughout the rainy season. This observation could be justified by the presence of frequent clouds events in the sky during the rainy season. The integration of cloud cover parameters in the model could correct this overestimation.

The error obtained in this study were compared to those observed by other authors who used the Angström formulation to estimate GSR in Africa. Adeyemi et al. [30] developed global solar radiation estimation models for the nine South African provinces using several meteorological parameters such as insolation, ambient temperature, relative humidity, and wind speed. The accuracy of the models was verified by comparing the estimated values with the measured values, using the following statistical error tests: mean bias error, mean absolute bias error, mean absolute percentage error, root mean square error. His results indicate that these error estimators range from $5.40 \%$ to $11.19 \%$ at the study sites. Adeniji et al. [31] estimated global solar radiation from the distribution of sunshine hours and the brightness index in Enugu (Nigeria). The authors then evaluated the margins of error between models and measurements and the values obtained did not exceed 2.5\%. Okundamiya and Nzeako [3] proposed a model based on the monthly mean global solar radiation temperature on horizontal surfaces for selected cities, representing the six geopolitical zones of Nigeria. The results of three statistical indicators: mean bias error (MBA), root mean square error (RMSE) and $t$-statistic test (TS) evaluated indicate that the RMSE and MBA ranged from 0.0023 at the Benin City site, 0.2685 for Katsina site. Quansah et al [10] after estimating global solar radiation by empirical models in the Ashanti region of Ghana obtained error estimators mean percentage error (MPE), mean bias error (MAE) and root mean square error (RMSE)) ranging from 0.0102 to 1.7075 .

Coulibaly and Ouedraogo [15] correlated the global solar radiation of eight synoptic stations in Burkina Faso based on linear and multiple linear regression methods. The results show that the relative errors obtained range from $3.16 \%$ to $3.65 \%$ in Dedougou. In the study of Ajayi et al. [22], the authors proposed five models for estimating 
global solar radiation over 12 sites spread over the six geopolitical zones in Nigeria based on the solar fraction, maximum temperature, relative humidity, the latitude of the site. The estimation errors of these models vary between $3.910^{-5}$ and 0.36 . In the study of Asilevi et al. [5], the global solar radiation in Ghana was quantified using the Angström-Prescott sunshine model and sunshine duration data from 22 synoptic stations distributed over the ecological zones of the country. The absolute mean percentage error obtained by the authors range from $3 \%$ to $29 \%$. Onyango and Ongoma [16] estimated the global solar radiation potential over the city of Nairobi. Hassan et al. [20] have presented new ambient temperature-based models for estimating global solar radiation at several sites in Egypt as alternatives to the widely used sun-based models due to the unavailability of solar radiation's data. Seventeen new temperature-based models are established, validated, and compared to the three other models proposed in the literature to estimate monthly mean daily global solar radiation on a horizontal surface. The estimation errors of these models range from 0.006 to 0.70 . Solar irradiation data recorded in three localities (Lomé, Atakpame, and Mangue) representing the climate and geographical areas of Togo were analyzed by Banna and M. Gnininri [32]. The monthly daily global radiation on a horizontal surface for the three cities is deduced from the relative sunshine data using the method developed by Angstrom. Appropriate regional parameters are determined and used to predict the solar irradiation in the three localities with an error of less than $8 \%$.

Because of these various studies, one can see that the performance of solar radiation estimation models vary from one site to another. Some values of the error estimators found in the literature are higher than those observed in the current study, especially at some sites in Egypt, Nairobi, Ghana, Nigeria, and South Africa. Others, on the other hand, are lower than the estimators obtained in Nalohou, particularly in Dedougou sites in Burkina Faso, Enugu in Nigeria, and at other sites in Ghana, Nigeria, and Egypt. However, models with margins of error of 10 to at most $20 \%$ have been approved and validated by the various authors. Given these observations, the errors in the estimation of global solar radiation presented at the Nalohou site are tolerable and thus allow us to confirm the performance of the proposed model. The margins of error of the model estimation is tolerable as they are of the order of $10^{-1}$ to $10^{-2}$. However, this model could be improved by integrating meteorological parameters such as aerosol content in the atmosphere and cloud cover data.

In Table 2, the values of the calibration constants of the proposed model are presented

Table 2: Model fitting constant

\begin{tabular}{|c|c|c|c|c|c|c|}
\hline \multicolumn{8}{|c|}{ Proposed model (Nalohou) } \\
\hline Constant & $\mathrm{a}$ & $\mathrm{b}$ & $\mathrm{c}$ & $\alpha$ & $\mathrm{d}$ & $\mathrm{e}$ \\
\hline Along year & 0.0571 & 0.1589 & 0.3739 & 0.7216 & 0.0173 & 0.0021 \\
\hline
\end{tabular}


Figure 6 presents the validation of the proposed model.
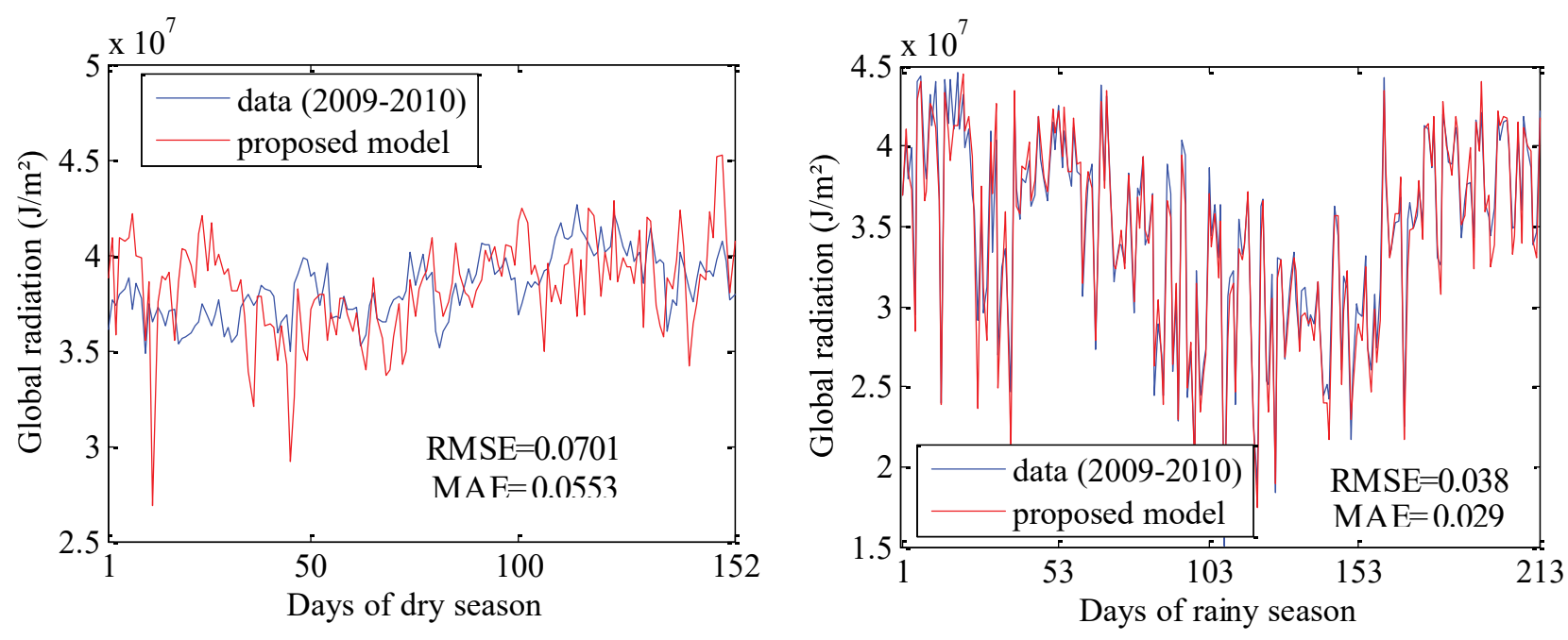

Figure 6: Validation of the proposed model (2009-2010)

The estimation errors (RMSE; MAE) of global solar radiation obtained from the proposed model and the data measured over the period from 10 July 2009 to 10 July 2010 are 0.0701 and 0.0553 for the dry season; they are 0.038 and 0.029 for the rainy season. These small margins of error allow us to validate the proposed model, which can now be used in this region of north west Benin as a model for estimating global solar radiation.

\subsection{Estimation of global solar radiation}

Based on the proposed model, the estimated global solar radiation at Natitingou synoptic station is presented in Figure 7 for an entire year (2016).

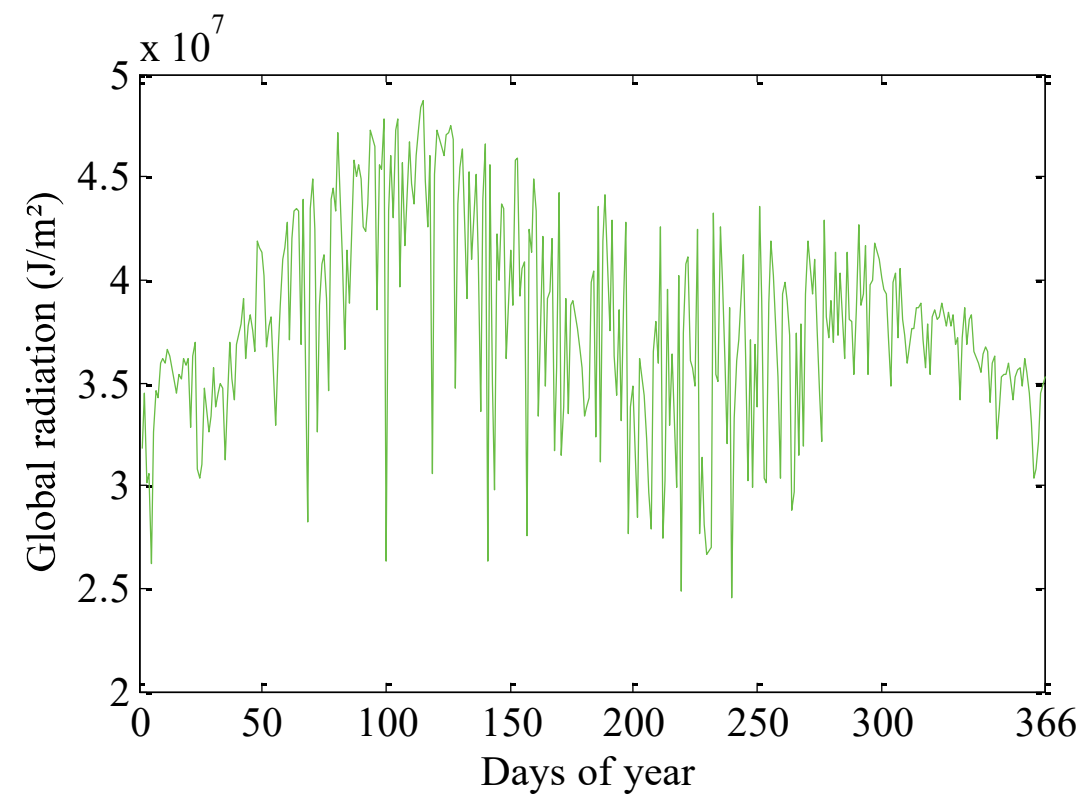

Figure 7: Daily variation in global solar radiation at Natitingou (2016) 
In Figure 7, the estimated global solar radiation at the Natitingou meteorological station is of the same order of magnitude as that measured at Nalohou but varies between $2.45 \times 10^{7} \mathrm{~J} / \mathrm{m}^{2}$ and $4.86 \times 10^{7} \mathrm{~J} / \mathrm{m}^{2}$ (i.e. $6.80 \mathrm{kWh} / \mathrm{m}^{2}$ to $13.5 \mathrm{kWh} / \mathrm{m}^{2}$ or $283.56 \mathrm{~W} / \mathrm{m}^{2}$ to $562.50 \mathrm{~W} / \mathrm{m}^{2}$ ) as opposed to the Nalohou site where measurements are between $1.79 \times 10^{7} \mathrm{~J} / \mathrm{m}^{2}$ and $4.53 \times 10^{7} \mathrm{~J} / \mathrm{m}^{2}$. The annual average global solar radiation is estimated at $3.78 \times 10^{7} \mathrm{~J} / \mathrm{m}^{2} \quad\left(10.50 \mathrm{kwh} / \mathrm{m}^{2}\right)$ at Natitingou and $3.53 \times 10^{7} \mathrm{~J} / \mathrm{m}^{2} \quad\left(9.80 \mathrm{kWh} / \mathrm{m}^{2}\right)$ at Nalohou. There is therefore a slight increase in GSR at Natitingou. The range of global solar radiation observed in this region of north -western Benin is therefore very useful for designers and installers of solar systems, which now have a reliable database of solar radiation that can be used for all purposes.

\section{Conclusion}

At the Nalohou site in northern Benin, a model for estimating global solar radiation was developed and validated using solar radiation data recorded at this site. Based on the proposed model, global solar radiation was estimated at the Natitingou site, which has climatic similarities to the Nalohou site. The main results of this study indicate that the annual average global solar radiation observed in the north-western region of Benin varies between $3.53 \times 10^{7} \mathrm{~J} / \mathrm{m}^{2}$ and 3.78 $\mathrm{X} 10^{7} \mathrm{~J} / \mathrm{m}^{2}\left(9.80 \mathrm{kWh} / \mathrm{m}^{2}\right.$ to $\left.10.5 \mathrm{kWh} / \mathrm{m}^{2}\right)$. The proposed global solar radiation estimation model can be used with a small margin of error of 8 to $10 \%$ throughout the year. During the dry and rainy season, the model can reproduce the measurements with an error of $2 \%$ to $3 \%$ respectively. However, the model could always be improved by combining aerosol content and cloud cover data, which are two parameters that influence the radiative fluxes received on the ground in our study area.

As a result of this study, a reliable database of global solar radiation is now available to solar system designers and installers to better size their installations.

\section{References}

[1] C. Schillings, R. Meyer, F. Trieb, Solar and wind energy resource assessment (swera), HighResolution Solar Radiation Assessment for Kenya. Final country report prepared by DLR-submitted to UNEP/GEF, 2004.

[2] B. Safari and J. Gasore, "Estimation of Global Solar Radiation in Rwanda Using Empirical Models", Asian Journal of Scientific Research, vol 2, pp68-75, 2009.

[3] S. Okundamiya and A. N. Nzeako, "Empirical model for estimating global solar radiation on horizontal surfaces for selected cities in the six Geopolitical zones in Nigeria" Journal of Control Science and Engineering, Vol 2011, Article ID 356405, pp1-7 2011.

[4] E. O. Falayi and A. B. Rabiu, "Estimation of global solar radiation using cloud cover and surface temperature in some selected cities in Nigeria" Archives of Physics Research, vol.2, no.3, pp.99109, 2011. 
[5] P. J. Asilevi, E. Quansah, L. K. Amekudzi, T. Annor, N. A. B. Klutse, "Modeling the spatial distribution of Global Solar Radiation (GSR) over Ghana using the Angström-Prescott sunshine duration model" Scientific African vol.4, 2019, e0 0094.

[6] A. M. Muzathik, W. B. W. Nik, M. Z. Ibrahim, K. B. Samo, K. Sopian, and M. A. Alghoul, "Daily global solar radiation estimate based on sunshine hours", International Journal of Mechanical and Materials Engineering, vol.6, no.1, pp.75-80, 2011.

[7] A. A. Trabea and M. A. M. Shaltout, "Correlation of global solar radiation with meteorological parameters over Egypt", Renewable Energy, vol 21, no.2, pp. 297-308, 2000.

[8] E. B. Pereira, F. R. Martins, S. L. Abreu, H. G. Beyer, S. Colle, R. Perez, D. Heinemann, "Crossvalidation of satellite radiation models during SWERA project in Brazil", in Proceedings of the ISES Solar World Congress, pp.14-19, Göteborg, Sweden, June 2003.

[9] M. J. Ahmad and G. N. Tiwari, "Solar radiation models a review" International Joumal of Energy Research, vol.35, no.4, pp.271-290, 2011.

[10] E. Quansah, L. K. Amekudzi, K. Preko, J. Aryee, O. R. Boakye, D. Boli, and M. R. Salifu, "Empirical models for estimating global solar radiation over the Ashanti region of Ghana", Journal of Solar Energy, vol 2014, Article ID 897970, pp1-6, 2014.

[11] L. E. Akpabio, S. O. Udo, and S. E. Etuk, "Empirical correlations of global solar radiation with meteorological data for Onne, Nigeria", Turkish Journal of Physics, vol.28, no.3, pp. 301-307, 2004 [12] E. O. Falayi and A. B. Rabiu, "Modeling global solar radiation using sunshine duration data", Nigeria Journal of Physics, vol 17, pp. 181-186, 2005.

[13] E. O. Falayi, J. O. Adepitan, and A. B. Rabiu, "Empirical models for the correlation of global solar radiation with meteorological data for Iseyin, Nigeria, "International Journal of Physical Sciences, vol. 3, no. 9, pp. 210-216, 2008.

[14] A. Karoro, T. Ssenyonga, J. Mubiru, "Predicting global solar radiation using an artificial neural network single-parameter model", Adv Artif Neutral Syst, pp 1-7, September 2011.

[15] O. Coulibaly and A. Ouedoraogo, "Correlation of global solar radiation of eight synoptic stations in Burkina Faso based on linear and multiple linear regression methods", J Sol Energy, pp1-12. January 2016.

[16] A. O. Onyango and V. Ongoma, "Estimation of mean monthly global solar radiation using sunshine hours for Nairobi City, Kenya", J Renew Sustain Energy, vol 7, n5, pp 1-11. 2015.

[17] A. Yisehak, "Comparison of different empirical models in the estimation of mean global solar radiation using sunshine duration measure at Dire Dawa, Ethiopia". Published MSc. Project 2014, pp 1-63.

[18] D. Afungchui and R. N. Neba, "Global solar radiation of some regions of Cameroon using the linear Angstrom and non-linear polynomial relations (Part 1) models development", Int $J$ Renew Energy Res. Vol 3, n 4, pp 984-92, 2013.

[19] A. A. Adeola, Z. Huan, C. C. Enweremadu, "Evaluation of global solar radiation using multiple weather parameters as predictors for South Africa Provinces", Therm Sci, vol 19, pp 495-509, 2015. [20] G. E. Hassan, M. E. Youssef, E. Mohamed, M. A. Ali and A. A. Hanafy, "New Temperaturebased Models for Predicting Global Solar Radiation", Applied Energy vol 179, pp 437-450. 2016. [21] M. Dankassoua, "Etude du rayonnement solaire global à Niamey de la période de prémousson et de la mousson de l'année 2013 (mai à octobre) ", Revue des Energies Renouvelables, vol 20, n¹, pp $131-146,2017$.

[22] O. O. Ajayi, O. D. Ohijeagbon, C. E. Nwadialo, O. Olasope, "New model to estimate daily global solar radiation over Nigeria". Sustainable Energy Technol, vol 5, pp 28-36, 2014. 
[23] B. M. Olomiyesan, D. Onyedi, O. D. Oyedum "Comparative study of ground measured, satellite-derived, and estimated global solar radiation data in Nigeria". J Sol Energy, 2016. Pp 1-7, 2016.

[24] S. Amoussa, "Estimation of global radiation in Benin". Renewable Energy, Vol 2, №3, pp311-317, 1992.

[25] O. Mamadou (2014) Etude des Flux d' Evapotranspiration en Climat Soudanien: comportement comparé de deux couverts végétaux au Bénin. Thèse de doctorat, Université de Grenoble, France.

[26] N. S. Chukwujindu, "A comprehensive review of empirical models for estimating global solar radiation in Africa", Renewable and Sustainable Energy Reviews, vol 78, pp 955-995, 2017.

[27] K. Hinrichsen, "The Ångström formula with coefficients having a physical meaning, Solar Energy Vol 52, Issue 6, pp 491-495, 1994.

[28] R. Tadili and M. N. Bargach, "Une méthode d'estimation du rayonnement solaire global reçu par une surface inclinée Application aux sites marocains", La Météorologie - $n^{\circ} 50$, pp 4650, 2005.

[29] J. C. Lagarias., J. A. Reeds, M. H. Wright, and P. E. Wright, "Convergence Properties of the Nelder-Mead Simplex Method in Low Dimensions", SIAM Journal of Optimization, vol. 9, $\mathrm{n}^{\circ} 1$, pp. 112-147, 1998.

[30] Adeyemi, Adeola, Z. Huan and C. C. Enweremadu, "Evaluation of global solar radiation using multiple weather parameters as predictors for south Africa provinces", Thermal Science, Vol. 19, Suppl. 2, pp. S495-S509, 2015.

[31] N. O. Adeniji, J. A. Akinpelu, S. O. Adeola, J. O. Adeniji, "Estimation of Global Solar Radiation, Sunshine Hour Distribution and Clearness Index in Enugu, Nigeria", J. Appl. Sci. Environ. Manage, Vol. 23 (2), pp. 345-349, 2019.

[32] M. Banna and M. Gnininri, "Estimation of monthly average hourly and daily global irradiance in Togo", RERIC International Energy Journal, vol 20, n¹, pp 21-37,1998. 